\title{
A Perspective From the Middle East on the Topic of Concussion
}

\author{
Z. Chemali ${ }^{1,2}$, F. Ezzeddine ${ }^{3}$, R. Tcheroyan ${ }^{4} \&$ D. Acar $^{2,5}$ \\ ${ }^{1}$ Massachusetts General Hospital, Departments of Neurology and Psychiatry, 55 Fruit Street, Boston, MA 02114, \\ USA \\ ${ }^{2}$ Harvard Medical School, 25 Shattuck Street, Boston, USA \\ ${ }^{3}$ Harvard T.H Chan School of Public Health, 677 Huntington Avenue, Boston, USA \\ ${ }^{4}$ American University of Beirut School of Medicine, Bliss Street, Beirut, Lebanon \\ ${ }^{5}$ Brigham and Women's Hospital, Neurology Department, 75 Francis Street, Boston, USA \\ Correspondence: Chemali Z, Massachusetts General Hospital, Departments of Neurology and Psychiatry, 55 Fruit \\ Street, Boston, MA 02114, USA. E-mail: zelchemali@mgh.harvard.edu
}

Received: February 2, 2020 Accepted: March 19, 2020 Online Published: April 7, 2020

doi:10.5539/gjhs.v12n6p30 URL: https://doi.org/10.5539/gjhs.v12n6p30

\begin{abstract}
Background: Concussion is the most prevalent form of traumatic brain injury. Western countries debate it as a public health issue. Middle Eastern (ME) countries lag behind with a concussion incidence surveillance of $25 \%$ that of European countries.
\end{abstract}

Objective: The purpose of our study was to review concussion resulting from traumatic brain or sports injuries in civilian nationals of the ME.

Methods: We carried out PubMed literature search of all related articles in the past thirty years using search terms reflecting concussion and sports injuries in ME countries of Bahrain, Egypt, Iran, Iraq, Israel, Jordan, Kuwait, Lebanon, Oman, Palestine, Qatar, Saudi Arabia, Syria, Turkey, United Arab Emirates, and Yemen.

Results: 72 articles met our search criteria with relatively little data found on concussion within the parameters of this review. However, the reports that were found were diverse. Israel, Turkey and Iran led in publications. Motor vehicle accidents were the leading cause of concussion from TBI (50-57\%) followed by domestic injuries (30-40\%) and sports injuries at 4-7\%. Extremity injuries were most commonly reported unlike head injuries often invisible and underreported. Male gender, young children, pedestrian and car traffic accidents, lack of protective gear, cell phone use, impulsive behaviors as well as training overload, lack of sleep, contact sports and violence were all risk factors for concussion.

Conclusions: In this review, we highlighted the nascent topic of concussion in the ME and the need for additional research dictating awareness programs and implementing new safety policies to lower morbidity and mortality across all ages.

Keywords: concussion, sports injuries, traumatic brain injury, Middle East

\section{Introduction}

Concussion is the most common form of traumatic brain injury (TBI) and is often defined as mild TBI (mTBI) with disruption in the normal function of the brain that can be caused by a blow, or a jolt to the head, or a penetrating head injury (Kazl \& Torres, 2019). In the past decade, it has attracted more attention in Western countries given its close relationship to sports injury. Experts from leading health organizations now consider concussion as a major public health issue affecting all ages. Despite the growing awareness in Western countries, many countries still face an underreporting in their concussion incidence surveillance. The lack of surveillance on concussion has led to a reported incidence at $25 \%$ value of the reported European incidence for the same sport. (Eiral et al., 2015). This paper is intended to review the topic of concussion in general and concussion as it relates to sports injury in the Middle East (ME). Controversies surround which countries are included in the ME. For the sake of this review, we will use ME as defined by Bahrain, Egypt, Iran, Iraq, Israel, Jordan, Kuwait, Lebanon, Oman, Palestine, Qatar, Saudi Arabia, Syria, Turkey, United Arab Emirates, and Yemen (Britannica E. Middle East, 2014). 


\section{Methods}

A literature search was performed in PubMed to identify relevant articles published within the past thirty years (January 1988 - till present). The following search (MeSH) terms were used: ("COUNTRY" (MeSH Terms) OR "COUNTRY" (All Fields)) AND ("brain concussion" (MeSH Terms) OR ("brain" (All Fields) AND "concussion" (All Fields)) OR "brain concussion" (All Fields) OR "concussion" (All Fields)). In addition, ("COUNTRY" (MeSH Terms) OR "COUNTRY" (All Fields)) AND ("sports" (MeSH Terms) OR "sports" (All Fields) OR "sport" (All Fields)) AND ("wounds and injuries" (MeSH Terms) OR ("wounds" (All Fields) AND "injuries" (All Fields)) OR "wounds and injuries" (All Fields) OR “injury"(All Fields)). The search yielded 528 articles (403 concussion as it relates to general concussion and TBI and 125 concussion and sports injury). Articles were excluded if they were not related to humans, if they were related to military; if the research was not related to citizens of the country; if the countries in ME pooled and counted multiple times; if they were not written in the English language; if the authors are from ME but the study is not conducted in a country of the ME; if the name of the author or country were pooled interchangeably (e.g. Jordan as country and Jordan as author; Israel as a country and Beth Israel as a hospital in USA); or if the topics were not primarily focused on brain injuries and dealt with injuries to muscles and extremities, spinal cord injuries, dental injuries without craniofacial injuries. All selected abstracts were further reviewed and relevant data was consolidated in this review. We were left with 72 articles from the respective countries as follows: Yemen (1), UAE (3), Turkey (14), Saudi (1), Qatar (8), Oman (2), Lebanon (4), Kuwait (1), Jordan (3), Israel (21), Iraq (1), Iran (10), Egypt (3). Syria, Palestine and Bahrein had no article remaining in the pool after the exclusions were applied. (See Figure 1)

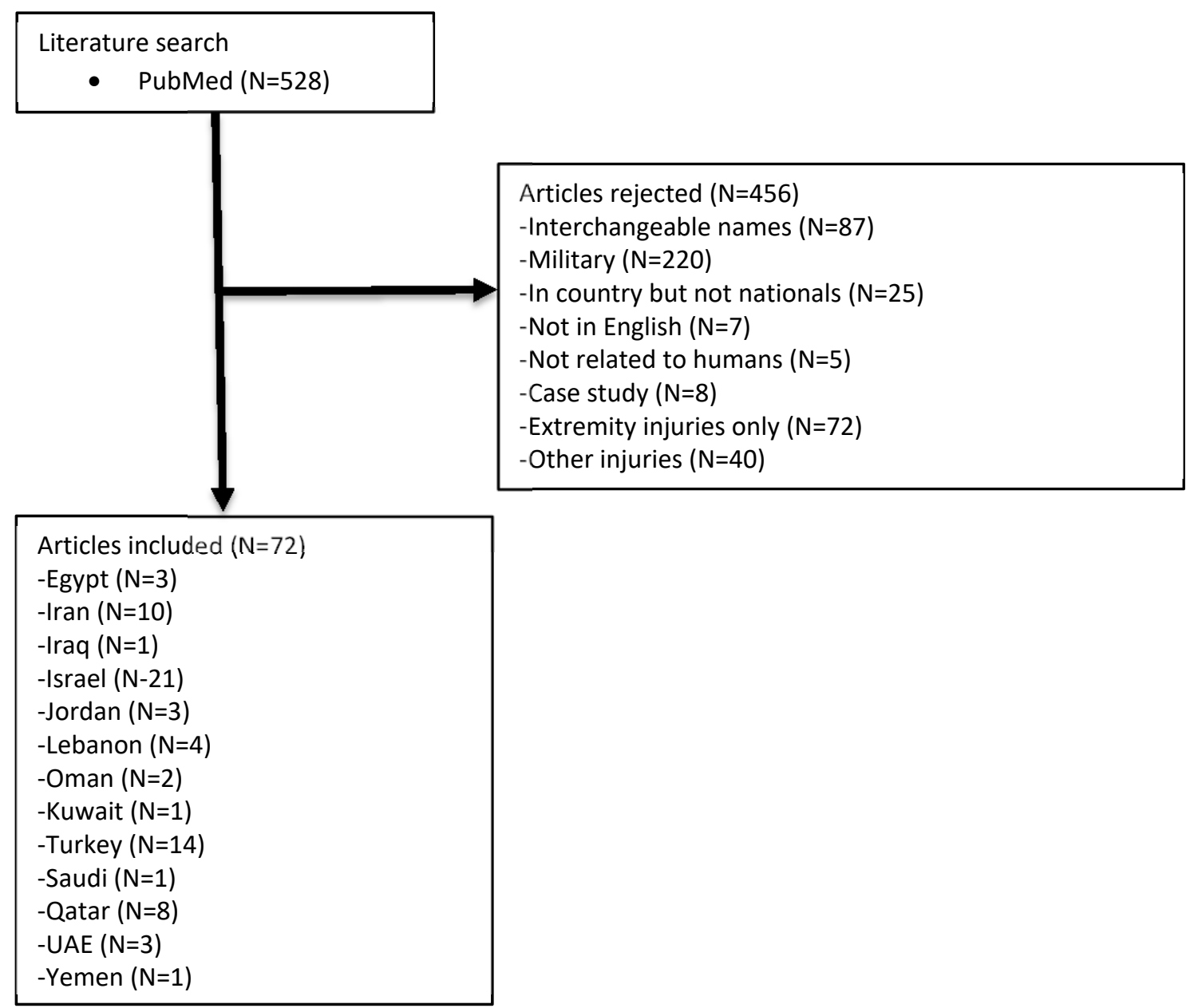

Figure 1. Flowchart of literature review 


\section{Results}

Overall, there was relatively little data found on concussion within the parameters of this review. However, the reports that were found were diverse.: from kickboxing and TBI in Qatar and Turkey (Slimani et al., 2017; Tanrivedi et al., 2007), fishing and aerial sport injuries as well as boxing related injuries in Turkey (Aydin, 2019; Cevik et al., 2016; Tanrivedi et al., 2008), to contact football and other team balls in Iran and Israel (Kordi et al., 2013; Kaplan et al., 2013), to new data on E-Biking with resulting serious injuries in Israel and Iran (Gross et al., 2018; Vahdati et al., 2016), rollover crashes as well as injuries related to Taekwondo and Karate in Iran (Anarkooli et al., 2017; Ziaee et al., 2010; Halabchi et al., 2007) and lastly camel jockeying injury in United Arab Emirates (UAE) (Abu-Zidan et al., 2012). Many countries focused on extremity injuries and were keen on detailing those injuries specifically; while data regarding head injury on the other hand was relatively sparse. Concussion from mild traumatic brain injury (mTBI) is invisible and often under-reported by victims due to not only the stigma surrounding brain dysfunction and wanting to remain in the sport, but also due to the insufficient research and surveillance methods that record concussive signs and symptoms. Concussions resulting from any traumatic brain injuries were divided into motor vehicle accident (MVA) injuries, reported at 50-57\%, domestic injuries (home injuries and falls) at 30-40\% and sports injuries reported only at $4-7 \%$. Most countries in the Middle East reported more injuries in males (at times 4x more than females) (Al-Balushi et al., 2012) Qatar focused on trends in sport injury; they found sports injury to be linked mainly to poor load management, pre-competition training and during play resulting in calendar congestion, and training overload and disrupted sleep (Schwellnus et al., 2016). Lebanon's research points to increased risk in traumatic brain concussion injury for those with diabetes and previous psychiatric history (Abou-El-Hassan et al., 2017). A large study in Lebanon also tackled head injuries in the ultimate fighting championship (UFC) and concluded that mixed martial arts (MMA) had a high injury rate with head injury being the highest at $67 \%$ with increase in weight division yielding to an increase rate of overall injuries and head injuries (Fares, 2019). Israeli research reports on increased comorbidity with PTSD and anxiety and repeated emergency visits. Iranian and Egyptian studies specifically reported face injury increasing the risk for head injury (Zandi $\mathrm{M}$ et al., 2013). Many studies in different countries reported on severe concussion in kids especially during collisions because of higher head/body ratio. Some countries were more interested in mTBI research (Israel and Qatar) and novel treatment options, such as hyperbaric chambers, though the outcome has not been validated and remains case-by-case referral with unimpressive outcomes so far. (Tal et al., 2015). Turkey was the only country that reported on neuroendocrine issues related to concussion injuries. The research in this area was abundant, especially pointing to mTBI in chronic head trauma in boxing, with altered pituitary function, low levels of growth hormones and a small size pituitary (Temizkan et al., 2019; Hacioglu et al., 2019). On the other hand, Iranian researchers were interested in post-traumatic headache in athletes (Jahani et al., 2016) concluding that its incidence was low unless the sport was wrestling, and that post-traumatic headache was an indicator for post-concussion recovery. They used Sport Concussion Assessment Tool 3 (SCAT-3) as a screening tool and found it valid and reliable (Khazaei et al., 2017).

\section{Special Considerations for Children and Elderly}

Research in ME reported that concussion in children were mainly due to domestic injuries (54.7\%) with road traffic (40\%) a close second (Crankson, 2006; Atwa et al., 2017; Alyafei et al., 2015). Aside from those common contexts, reported child concussions were related to war violence and cluster bombs (Fares et al., 2013) in Lebanon, corporeal punishment in schools in Egypt (Youssef et al., 1998) and baby walker injuries leading to $82 \%$ head injuries in Iraq (Al Nouri \& Al-Isami, 2006). Jordan was the only country to tackle sickle cell anemia as increased risk for athletic injuries in adolescent athletes (Al- Rimawi \& Jallad, 2008). Camel Jockeying was reported in UAE with death and morbidity rising among kids leading to the implementation of a law pushing for a robotic substitute to ride the camels (Abu-Zidan et al., 2012).

In our review, we found that publications on elders' concussion injuries were rare in most ME countries. When published, elders suffered mostly from road traffic concussion injuries followed by falls. As a special note although older adults are recommended to be more active and maintain increased physical activity beneficial to their brain health and cardiovascular systems, there needs to be a parallel assessment of the risk of injuries relative to the extent of the prescribed exercise routine and elders' functional status.

\section{Discussion}

The Middle East and North African (MENA) countries have been involved in large review and collaborative spine care initiative for the past few years (Elshaidi et al., 2018). Having said that, mild traumatic brain injury and concussion remain the silent epidemics over the past decade continuing onto this present time. While few countries in the ME have taken a lead to address those issues such as Iran, Israel and Turkey, many ME countries still lag in 
reporting despite available resources to do so (Qatar, Saudi, UAE) while others are not represented at all (Palestine, Syria, Bahrein). Although concussion injuries may be invisible to the naked eye, they affect victims both cognitively and emotionally and for a long period of time (Heim et al., 2017). Road traffic accidents (pedestrians and cyclists) remain by far the leading cause for concussion injuries at all ages. Falls, gunshot, violence and sports injury follow (Elshaidi et al., 2018). Although our review on concussion in ME countries revealed diverse topics, the numbers of published manuscripts for the 371 million inhabitants of the ME is clearly suboptimal. Under-reporting is widely noted and causes a major hurdle for accurate and meaningful research. Iran was the only country in ME to invest in examining whether the data collection and interpretation was indeed as meaningful as currently studied. (Nielsen et al., 2018; Gitelman et al., 2019).

From the data collected in this review, gender, children (due to higher ratio of head/body surface), traffic accidents, pedestrian status, lack of protective gear, use of cell phone, risky behaviors, training overload, lack of sleep, contact sports and violence are all risk factors for concussion. These risk factors are indeed preventable. Interestingly, most countries reported a higher prevalence of head injuries in males, most likely due to cultural and gender differences in interacting with the outside world, participation in sport activities and increased risk-taking behaviors. In addition, adolescent males were reported to have high-risk behaviors in general and easily distracted by cellphone use e.g. when crossing streets (although the excessive use of cell phone was found in both genders) (Nielsen et al., 2019). New initiatives such as pre-training programs to minimize the risk for injury are being promoted (Al. Attar et al., 2017) and the redactions of new policies for traffic (motor vehicles, cyclists and pedestrians) are underway. Indeed, policy to address concussion as a system issue is warranted. Consensus papers have emanated from Qatar and Israel while Egypt and Saudi Arabia drafted policies in the prevention of road accidents. (Crankson SJ, 2006) A policy is in effect for the mandatory wearing of helmets by cyclists in Iran and Israel after $100 \%$ of bike concussion injuries were reported in cyclists without helmet protection (Vahdati et al., 2016; Siman-Tov \& Jaffe, 2012; Gitelman et al., 2012).

\section{Limitations}

This review has limitations given that some will view it as overly broad. We intended it as such as publications from the Middle East related to civilian injuries (be it concussion from TBI or sports injury) are scarce while the topic is highly written about for military personnel. It is the same reason why we chose the span of 30 years to report on despite knowing that defining head injury or TBI-concussion have changed throughout the years. In addition, we acknowledge that the system of care in the Middle East differs from country to country and could go beyond shared cultural issues contributing to barriers in addressing this particular public health issue. Finally, the mansucript does not intend to be a highly specialized review on the topic. Its goal is to be a meaningful compact read that would start the exploration and a rigorous research about the topic in the region of the ME.

\section{Conclusion}

In this review, we highlighted the nascent research of concussion in the ME. It is vital that all nations advance the research, outreach, campaign and policy surrounding concussion in general, including sports-related concussions within the whole age spectrum. This review points to systemic issues related to surveillance, traffic violation, lack of protective gear, use of cell phones, domestic violence and wars as identified risk factors for concussion. There is a dire need to move from spot emergency treatment to addressing the system issues facing concussion of all types, treating patients' symptoms and finding the root cause to address system failures. A systemic inquiry leading to new policy transforming and impacting this field would be implemented to diminish mortality, morbidity and stigma following those preventable injuries. Needless to say, if we could attend to those systemic issues and prevent the most adverse effects of concussion, the public health impact would be significant in lowering mortality and morbidity for all, increasing academic performance of children and adolescents, allowing for safe sport practices for all athletes and preventing serious long-term repercussion of brain injury in the region.

\section{Competing Interests Statement}

The authors declare that there are no competing or potential conflicts of interest.

\section{References}

Abou-El-Hassan, H., Dia, B., Choucair, K., Eid, S. A., Najdi, F., Baki, L., ... \& Kobeissy, F. (2017). Traumatic brain injury, diabetic neuropathy and altered-psychiatric health: The fateful triangle. Medical hypotheses, 108, 69-80. https://doi.org/10.1016/j.mehy.2017.08.008

Abu-Zidan, F. M., Hefny, A. F., \& Branicki, F. (2012). Prevention of child camel jockey injuries: a success story from the United Arab Emirates. Clinical journal of sport medicine, 22(6), 467-471. https://doi.org/10.1097/JSM.0b013e318258772a 
Al Attar, W. S. A., Soomro, N., Pappas, E., Sinclair, P. J., \& Sanders, R. H. (2017). Adding a post-training FIFA $11+$ exercise program to the pre-training FIFA 11+ injury prevention program reduces injury rates among male amateur soccer players: a cluster-randomised trial. Journal of physiotherapy, 63(4), 235-242. https://doi.org/10.1016/j.jphys.2017.08.004

Al-Balushi, H., Al-Kalbani, A., Al-Khwaldi, T., Al-Suqri, S., Al-Maniri, A., Alazri, M., \& Al-Hinai, M. (2012). Injuries presented at a primary care setting in Oman. Oman medical journal, 27(6), 486. https://doi.org/10.5001/omj.2012.116

Al-Rimawi, H., \& Jallad, S. (2008). Sport participation in adolescents with sickle cell disease. Pediatric endocrinology reviews: PER, 6, 214-216.

Alyafei, K. A., Toaimah, F., El Menyar, A., Al Thani, H., Youssef, B., Mollazehi, M., \& Consunji, R. (2015). Analysis of pediatric trauma data from a hospital based trauma registry in Qatar. International journal of critical illness and injury science, 5(1), 21. https://doi.org/10.4103/2229-5151.152312

Anarkooli, A. J., Hosseinpour, M., \& Kardar, A. (2017). Investigation of factors affecting the injury severity of single-vehicle rollover crashes: a random-effects generalized ordered probit model. Accident Analysis \& Prevention, 106, 399-410. https://doi.org/10.1016/j.aap.2017.07.008

Atwa, H., AbdAllah, N., \& Abd El Gawad, H. (2017). Pattern and outcome of pediatric head injuries in the Suez Canal Region: A follow-up study. Journal of Egyptian Public Health Association, 92(1), 11-17. https://doi.org/10.21608/EPX.2018.6647

Aydin, S. (2019). Intracranial Penetrating Trauma Caused by Fishing Sinker. World neurosurgery, 129, 237-240. https://doi.org/10.1016/j.wneu.2019.06.051

Britannica. E. Middle East. (2014). The editors of Encyclopedia Britannica.

Cevik, A. A., Kaya, F. B., Acar, N., Sahin, A., \& Ozakin, E. (2017). Injury, hospitalization, and operation rates are low in aerial sports. Turkish journal of emergency medicine, 17(3), 81-84. https://doi.org/10.1016/j.tjem.2016.11.004

Crankson, S. J. (2006). Motor vehicle injuries in childhood: a hospital-based study in Saudi Arabia. Pediatric surgery international, 22(8), 641-645. https://doi.org/10.1007/s00383-006-1715-7

De Dhaem, O. B., Barr, W. B., Balcer, L. J., Galetta, S. L., \& Minen, M. T. (2017). Post-traumatic headache: the use of the sport concussion assessment tool (SCAT-3) as a predictor of post-concussion recovery. The journal of headache and pain, 18(1), 60. https://doi.org/10.1186/s10194-017-0795-1

Eirale, C., Tol, J. L., Targett, S., Holmich, P., \& Chalabi, H. (2015). Concussion surveillance: do low concussion rates in the Qatar Professional Football League reflect a true difference or emphasize challenges in knowledge translation?. Clinical journal of sport medicine, 25(1), 73-74. https://doi.org/10.1097/JSM.0000000000000066

Elshahidi, M. H., Monir, N. Y., Elzhery, M. A., Sharaqi, A. A., Haedaya, H., Awad, B. I., \& Zaghloul, K. (2018). Epidemiological characteristics of traumatic spinal cord injury (TSCI) in the Middle-East and North-Africa (MENA) Region: A systematic review and meta-analysis. Bulletin of Emergency \& Trauma, 6(2), 75. https://doi.org/10.29252/beat-060201

Fares, M. Y., Fares, J., Fares, Y., \& Abboud, J. A. (2019). Musculoskeletal and head injuries in the Ultimate Fighting Championship (UFC). The Physician and sportsmedicine, 47(2), 205-211. https://doi.org/10.1080/00913847.2018.1546108

Fares, Y., Ayoub, F., Fares, J., Khazim, R., Khazim, M., \& Gebeily, S. (2013). Pain and neurological sequelae of cluster munitions on children and adolescents in South Lebanon. Neurological sciences, 34(11), 1971-1976. https://doi.org/10.1007/s10072-013-1427-4

Fazen, L. E., \& Felizberto, P. I. (1982). Baby walker injuries. Pediatrics, 70(1), 106-109. https://doi.org/10.1179/146532806X90637

Gitelman, V., Balasha, D., Carmel, R., Hendel, L., \& Pesahov, F. (2012). Characterization of pedestrian accidents and an examination of infrastructure measures to improve pedestrian safety in Israel. Accident Analysis \& Prevention, 44(1), 63-73. https://doi.org/10.1016/j.aap.2010.11.017

Gitelman, V., Levi, S., Carmel, R., Korchatov, A., \& Hakkert, S. (2019). Exploring patterns of child pedestrian behaviors at urban intersections. Accident Analysis \& Prevention, 122, 36-47. 
https://doi.org/10.1016/j.aap.2018.09.031

Gross, I., Weiss, D. J., Eliasi, E., Bala, M., \& Hashavya, S. (2018). E-bike-related trauma in children and adults. The Journal of emergency medicine, 54(6), 793-798. https://doi.org/10.1016/j.jemermed.2017.12.012

Hacioglu, A., Kelestimur, F., \& Tanriverdi, F. (2019). Pituitary dysfunction due to sports-related traumatic brain injury. Pituitary, 22(3), 322-331. https://doi.org/10.1007/s11102-019-00937-z

Halabchi, F., Ziaee, V., \& Lotfian, S. (2007). Injury profile in women shotokan karate championships in Iran (2004-2005). Journal of sports science \& medicine, 6(CSSI-2), 52.

Heim, L. R., Bader, M., Edut, S., Rachmany, L., Baratz-Goldstein, R., Lin, R., ... \& Schreiber, S. (2017). The invisibility of mild traumatic brain injury: impaired cognitive performance as a silent symptom. Journal of neurotrauma, 34(17), 2518-2528. https://doi.org/10.1089/neu.2016.4909

Jahani, P., Salesi, M., Marzban, M., \& Abdollahifard, G. (2016). The prevalence of headache among athletic university students. Asian journal of sports medicine, 7(1). https://doi.org/10.5812/asjsm.33515

Kaplan, Y., Myklebust, G., Nyska, M., Palmanovich, E., Victor, J., \& Witvrouw, E. (2013). The epidemiology of injuries in contact flag football. Clinical Journal of Sport Medicine, 23(1), 39-44. https://doi.org/10.1097/JSM.0b013e3182694870

Kazl, C., \& Torres, A. (2019, July). Definition, Classification, and Epidemiology of Concussion. In Seminars in Pediatric Neurology (Vol. 30, pp. 9-13). WB Saunders. https://doi.org/10.1016/j.spen.2019.03.003

Kordi, R., Chitsaz, A., Rostami, M., Mostafavi, R., \& Ghadimi, M. (2013). Incidence, nature, and pattern of injuries to referees in a premier football (soccer) league: a prospective study. Sports health, 5(5), 438-441. https://doi.org/10.1177/1941738113481428

Nielsen, R. O., Chapman, C. M., Louis, W. R., Stovitz, S. D., Mansournia, M. A., Windt, J., ... \& Finch, C. F. (2018). Seven sins when interpreting statistics in sports injury science. https://doi.org/10.1136/bjsports-2017-098524

Nielsen, R. O., Debes-Kristensen, K., Hulme, A., Bertelsen, M. L., Møller, M., Parner, E. T., \& Mansournia, M. A. (2019). Are prevalence measures better than incidence measures in sports injury research?. https://doi.org/10.1136/bjsports-2017-098205

Schwellnus, M., Soligard, T., Alonso, J. M., Bahr, R., Clarsen, B., Dijkstra, H. P., ... \& Budgett R, Engebretsen. (2016). How much is too much? Br $J$ Sports Med, 50(17),1043-52. https://doi.org/10.1136/bjsports-2016-096572

Siman-Tov, M., Jaffe, D. H., Peleg, K., \& Israel Trauma Group. (2012). Bicycle injuries: a matter of mechanism and age. Accident Analysis \& Prevention, 44(1), 135-139. https://doi.org/10.1016/j.aap.2010.10.006

Slimani, M., Chaabene, H., Miarka, B., Franchini, E., Chamari, K., \& Cheour, F. (2017). Kickboxing review: anthropometric, psychophysiological and activity profiles and injury epidemiology. Biology of sport, 34(2), 185. https://doi.org/10.5114/biolsport.2017.65338

Tal, S., Hadanny, A., Berkovitz, N., Sasson, E., Ben-Jacob, E., \& Efrati, S. (2015). Hyperbaric oxygen may induce angiogenesis in patients suffering from prolonged post-concussion syndrome due to traumatic brain injury. Restorative neurology and neuroscience, 33(6), 943-951. https://doi.org/10.3233/RNN-150585

Tanriverdi, F., Unluhizarci, K., Coksevim, B., Selcuklu, A., Casanueva, F. F., \& Kelestimur, F. (2007). Kickboxing sport as a new cause of traumatic brain injury-mediated hypopituitarism. Clinical endocrinology, 66(3), 360-366. https://doi.org/10.1111/j.1365-2265.2006.02737.x

Tanriverdi, F., Unluhizarci, K., Kocyigit, I., Tuna, I. S., Karaca, Z., Durak, A. C., ... \& Kelestimur, F. (2008). Brief communication: pituitary volume and function in competing and retired male boxers. Annals of internal medicine, 148(11), 827-831. https://doi.org/10.7326/0003-4819-148-11-200806030-00005

Temizkan, S., \& Kelestimur, F. (2019). A clinical and pathophysiological approach to traumatic brain injury-induced pituitary dysfunction. Pituitary, 22(3), 220-228. https://doi.org/10.1007/s11102-019-00941-3

Vahdati, S. S., Ghafouri, R. R., Razavi, S., \& Mazouchian, H. (2016). Bicycle-Related Injuries Presenting to Tabriz Imam Reza Hospital, Iran. Trauma monthly, 21(2). https://doi.org/10.5812/traumamon.20856

Youssef, R. M., Attia, M. S. E. D., \& Kamel, M. I. (1998). Children experiencing violence II: Prevalence and determinants of corporal punishment in schools. Child Abuse \& Neglect, 22(10), 975-985. https://doi.org/10.1016/S0145-2134(98)00084-2 
Zandi, M., \& Hoseini, S. R. S. (2013). The relationship between head injury and facial trauma: a case-control study. Oral and maxillofacial surgery, 17(3), 201-207. https://doi.org/10.1007/s10006-012-0368-z

Ziaee, V., Rahmani, S. H., \& Rostami, M. (2010). Injury rates in Iranian taekwondo athletes; a prospective study. Asian journal of sports medicine, 1(1), 23.https://doi.org/10.5812/asjsm.34877

\section{Copyrights}

Copyright for this article is retained by the author(s), with first publication rights granted to the journal.

This is an open-access article distributed under the terms and conditions of the Creative Commons Attribution license (http://creativecommons.org/licenses/by/4.0/). 